\title{
The prevalence and factors associated with stunting among infants aged 6 months in a peri-urban South African community
}

\author{
Tonderayi M Matsungo ${ }^{1, *}$, Herculina S Kruger ${ }^{1}$, Mieke Faber ${ }^{1,2}$, Marinel Rothman ${ }^{1}$ and \\ Cornelius $M$ Smuts ${ }^{1}$ \\ ${ }^{1}$ Centre of Excellence for Nutrition, Internal Box 594, North-West University, PO Box X6001, Potchefstroom 2520, \\ South Africa: ${ }^{2}$ Non-Communicable Diseases Research Unit, South African Medical Research Council, Tygerberg, \\ South Africa
}

Submitted 10 November 2016: Final revision received 15 May 2017: Accepted 7 July 2017: First published online 7 September 2017

\begin{abstract}
Objective: To determine the prevalence and factors associated with stunting in 6-month-old South African infants.

Design: This cross-sectional study was part of the baseline of a randomized controlled trial. Weight-for-length, length-for-age and weight-for-age $Z$-scores were based on the WHO classification. Blood samples were analysed for Hb, plasma ferritin and soluble transferrin receptor (sTfR). Socio-economic, breast-feeding and complementary feeding practices were assessed by questionnaire.

Setting/Subjects: Infants aged 6 months ( $n$ 750) from a peri-urban area of Matlosana Municipality, North West Province of South Africa.

Results: Stunting, underweight, wasting and overweight affected 28.5, 11.1, 1.7 and $10 \cdot 1 \%$ of infants, respectively. Exclusive breast-feeding to 6 months of age was reported in $5.9 \%$ of the infants. Multivariable binary logistic regression showed that birth weight $(\mathrm{OR}=0 \cdot 12 ; 95 \% \mathrm{CI} 0 \cdot 07,0 \cdot 21, P<0 \cdot 001)$ and maternal height $(\mathrm{OR}=0.94 ; 95 \%$ CI $0.91,0.98, P=0.001)$ were inversely associated with stunting; while male sex $(\mathrm{OR}=1.73 ; 95 \%$ CI $1 \cdot 10,2 \cdot 70, P=0.014)$ was associated with higher odds for stunting. Stunting was also associated with higher plasma sTfR (>8.3 mg/l) concentrations.

Conclusions: The association between stunting and lower birth weight, shorter maternal height and male sex reflects possibly the intergenerational origins of stunting. Therefore, interventions that focus on improving preconceptual and maternal nutritional status, combined with strategies to promote appropriate infant feeding practices, may be an important strategy to prevent stunting in vulnerable settings.
\end{abstract}

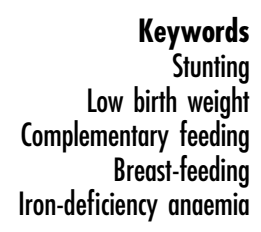

Stunting affects approximately 159 million children under 5 years old worldwide and a greater proportion of these children are in sub-Saharan Africa and south-central Asia ${ }^{(1)}$. Childhood stunting and micronutrient deficiencies are usually associated with poor nutrition and increased exposure to infections and unsanitary environments ${ }^{(2)}$. In South Africa, stunting remains the most prevalent form of undernutrition in children under 5 years ld $^{(3)}$. The results of the 2012 South African National Health and Nutrition Examination Survey (SANHANES) showed that stunting in South African children was highest in the age group of 0-3 years, 26.9 and $25.9 \%$ for boys and girls, respectively ${ }^{(4)}$.

In South Africa, malnutrition is often associated with sociodemographic factors, income level, weekly expenditure on food, employment status, education level of the mother and food insecurity ${ }^{(5)}$. Complementary foods commonly consumed are usually cereal based and deficient in key micronutrients ${ }^{(6,7)}$. This may result in increased risk of micronutrient deficiencies, resulting in a vicious cycle between malnutrition and infection that may be linked to the moderately high prevalence of stunting among South African children under 5 years of age ${ }^{(4)}$.

The relationship between stunting and sociodemographic, household and environmental determinants is still not clearly understood. Intergenerational factors such as maternal short stature may increase the risk of poor offspring birth outcomes and growth retardation ${ }^{(8-10)}$. Stunting begins in utero and is linked to maternal short stature ${ }^{(8-10)}$ and poor maternal nutrition $^{(2)}$, resulting in intra-uterine growth restriction and low birth weight. This points towards the importance of interventions from preconception through the $1000 \mathrm{~d}$ window period to prevent the intergenerational cycle of stunting. 
There is a need to understand the interplay between several factors associated with stunting to develop and scale up population-, sex- and age-specific interventions, and help to encrypt the multifaceted causal matrix. Studies on factors associated with stunting among children under 5 years within an age range ${ }^{(7,8,11)}$ have been published, but there is a lack of information about the prevalence and factors associated with stunting in specifically 6-month-old infants in developing countries. Therefore, the aim of the present study was to identify maternal, socio-economic, feeding practices and child characteristics associated with stunting among 6-month-old infants from a peri-urban area in South Africa. The data for the present study were collected as the baseline for a randomized controlled trial assessing the efficacy of lipid-based nutrient supplements on the growth of 6-month-old infants. The trial is registered (NCT01845610) at http://clinicaltrials.gov.

\section{Methods}

\section{Study site, sampling and participants}

The current paper presents data on the factors associated with stunting in 6-month-old black infants ( $n$ 750) using baseline data of a randomized controlled trial. The data were collected between September 2013 and January 2015 and the trial was carried out in the peri-urban area of Matlosana Municipality, North West Province of South Africa. Trained fieldworkers recruited potentially eligible mother-infant pairs through five primary health-care clinics and house-to-house visits. A total of 998 mother/caregiver-infant pairs were recruited, of whom 235 failed to come for the final screening visit and thirteen were excluded because they were not eligible to be included in the randomized controlled trial. The sample size ( $n$ 750) was based on sample size calculations for the randomized controlled trial, which had linear growth as the main outcome. The sample size was adequate for the cross-sectional analyses performed for the current study with the main aim to determine variables associated with stunting, assuming a probability of stunting of at least 0.2 and a minimum odds ratio of 1.3 (or 0.8 for an inverse association) at a type 1 error of $5 \%$ and power of $80 \%{ }^{(12)}$.

\section{Inclusion and exclusion criteria}

Black infants of age 6 months from a peri-urban area were enrolled in the study. Infants were excluded if they had never received any breast milk previously, had severe obvious congenital abnormalities, $\mathrm{Hb}<70 \mathrm{~g} / \mathrm{l}$, weightfor-height $Z$-score $<-3$, other diseases or recent hospitalization, if their caregiver planned to move out of the study area within the next 7 months, if they were receiving special nutritional supplements as part of feeding programmes, were diagnosed with HIV infection (we did not test for HIV status in the study), were known be allergic/intolerant to peanuts, soya, cow's milk protein or fish, or they had not been born as a singleton. Infants were enrolled if they came with the parent(s) or caregiver; however, for assessing maternal height, only data from biological mothers were used.

\section{Data collection, measurements and handling}

Weight and recumbent length were taken according to WHO standardized techniques ${ }^{(13)}$. The anthropometry assessors were trained according to the WHO Training Course on Child Growth Assessment for infants ${ }^{(14)}$. Infants were undressed and weighed to the nearest $0.01 \mathrm{~kg}$ using a digital baby scale (model 354, maximum weight $20 \mathrm{~kg}$; Seca GmbH \& Co. KG, Hamburg, Germany). Recumbent length was measured to the nearest $0 \cdot 1 \mathrm{~cm}$ using an infantometer (model 416; Seca). Mid-upper arm circumference was measured using a measuring tape (Seca 201) and head circumference was measured using a measuring tape (Seca 212). All measurements were done in duplicate and if the first two measurements differed by $>0.05 \mathrm{~kg}$ for weight or by $>0.2 \mathrm{~cm}$ for length or circumference, a third measurement was done, the two closest values were recorded and the means were calculated. The anthropometric indices, namely lengthfor-age $Z$-score (LAZ), weight-for-length $Z$-score (WLZ), weight-for-age $Z$-score (WAZ), head circumference-for-age $Z$-score (HCZ), BMI-for-age $Z$-score (BAZ) and mid-upper arm circumference-for-age $Z$-score (MUACZ), were generated using WHO Anthro 2005 software. Birth weight was obtained from the infant's Road-to-Health booklet.

The weight of mothers was measured to the nearest $0.01 \mathrm{~kg}$ using a digital adult scale (UC-321; Precision A\&D Company, Ltd, Tokyo, Japan), while the height of the mothers was measured using a mechanical stadiometer (Seca, Birmingham, UK) according to standard methods ${ }^{(15)}$. The standard formula, [weight $\left.(\mathrm{kg})\right] /[\text { height }(\mathrm{m})]^{2}$, was used to calculate $\mathrm{BMI}^{(16)}$. The scales were calibrated on a daily basis.

A set of unquantified FFQ was used to assess dietary intake of the infants during the past week $(7 \mathrm{~d})$. Breastfeeding and complementary feeding practices were assessed based on a WHO questionnaire ${ }^{(17)}$. The questionnaire also had questions on sociodemographic characteristics, water and sanitation, and size of households, and education, employment status and marital status of mothers/caregivers.

Anaemia and iron status were analysed from blood samples $(4 \mathrm{ml})$ which were collected via antecubital venepuncture into EDTA-coated trace-element-free evacuated tubes (Becton Dickinson, Franklin Lakes, NJ, USA) by the study nurse. In cases where obtaining a blood sample was not successful, a finger prick was performed to assess $\mathrm{Hb}$ status. Hb was determined for all infants ( $n$ 750) using a HemoCue machine (Ames Mini-Pak haemoglobin test pack and Ames Minilab; Bio Rad Laboratories (Pty) Ltd, Hercules, CA, USA). A blood sample was successfully obtained from 485 infants. Blood for later analyses was prepared by centrifuging at $500 \mathrm{~g}$ for $15 \mathrm{~min}$ at room temperature and aliquoted plasma was stored at $-80^{\circ} \mathrm{C}$ in temperaturemonitored freezers at North-West University (Potchefstroom, South Africa). For analysis, the samples were shipped 
to Vitmin Lab (Willstaett, Germany) as per shipment regulations and specifications of the National Department of Health. Plasma ferritin (PF) and soluble transferrin receptor (sTfR) concentrations were determined using a sensitive sandwich ELISA technique ${ }^{(18)}$. High-sensitivity C-reactive protein (CRP) and $\alpha_{1}$-glycoprotein (AGP) were measured with an ELISA kit from Human Diagnostics (Wiesbaden, Germany).

\section{Definitions}

Anthropometric status was assessed using the WHO Child Growth Standards ${ }^{(19)}$. Wasting was defined as WLZ $<-2$, stunting as $\mathrm{LAZ}<-2$, underweight as $\mathrm{WAZ}<-2$ and overweight as $\mathrm{WLZ}>+2^{(20)}$. Low birth weight was defined as birth weight below $2.5 \mathrm{~kg}$ regardless of gestational age ${ }^{(21)}$. Maternal short stature was defined as height below $150 \cdot 1 \mathrm{~cm}$, which is the median minus $2 \mathrm{sD}$ of the reference height for 18-year-old girls ${ }^{(22)}$. Anaemia was defined as $\mathrm{Hb}<11 \mathrm{~g} / \mathrm{dl}$, iron deficiency (ID-PF) as PF $<12 \mu \mathrm{g} / \mathrm{l}$ and iron-deficiency anaemia (IDA-PF) as both $\mathrm{PF}<12 \mu \mathrm{g} / \mathrm{l}$ and $\mathrm{Hb}<11 \mathrm{~g} / \mathrm{dl}^{(23,24)}$. ID-sTfR was defined as sTfR $>8.3 \mathrm{mg} / \mathrm{l}$ and IDA-sTfR was defined as both $\mathrm{Hb}<11 \mathrm{~g} / \mathrm{dl}$ and $\mathrm{sTfR}>8.3 \mathrm{mg} / \mathrm{l}$ (test-kit reference value). Inflammation was detected by acute-phase proteins, $\mathrm{AGP}>1 \mathrm{~g} / \mathrm{l}$ and $\mathrm{CRP}>5 \mathrm{mg} / \mathrm{l}^{(25)}$. Individual $\mathrm{PF}$ concentrations were adjusted by using correction factors specific to each individual's inflammatory status ${ }^{(25)}$.

\section{Statistical analysis}

Shapiro-Wilk test and Q-Q plots were used to check for normality of the continuous variables. Results are reported as the mean and standard deviation for continuous normally distributed data, or as the median and interquartile range for continuous non-normally distributed data. The independent $t$ test was used to test for significance of the difference between two means, the Mann-Whitney test for significance of differences between median values and the Pearson $\chi^{2}$ test for associations between categorical data. Univariate logistic regression analysis was done to explore and understand the relationships between variables and stunting. Factors significantly associated with stunting were then included in the multivariable binary logistic regression analysis with stunting (stunted $v$. non-stunted) as the dependent variable using the backward elimination technique. The factors that were included in the regression models were sex, birth weight $(\mathrm{kg}), \mathrm{Hb}(\mathrm{g} / \mathrm{dl})$, sTfR (mg/l), AGP (g/l), education level of the mother/caregiver and consumption of jarred commercial infant foods. Maternal height $(\mathrm{cm})$ was included in the final model based on theoretical evidence that the mother's stature influences birth outcomes and stunting $(8,10)$. Nagelkerke $R^{2}$ and the Hosmer and Lemeshow test were used to evaluate the goodness-of-fit of the model and as the basis for selecting the final model. The $P$ value, odds ratio and $95 \%$ confidence interval are reported for the respective regression coefficients. For all analyses, statistical significance was set at $P<0.05$. In univariate logistic regression $P<0 \cdot 10$ was used as a cut-off point to retain variables in the regression model. The data were analysed using the statistical software package IBM SPSS Statistics version 23.

\section{Results}

A total of 750 infants (387 boys, 363 girls) with a mean age of 6.2 (SD 0.3$)$ months participated in the study. Significantly more boys than girls were stunted $(32 \cdot 0 \mathrm{v}$. $24.8 \%, P=0.028)$. Low birth weight was recorded in $14.0 \%$ of the infants and of these $58.8 \%$ were stunted compared with $41.2 \%$ who were not stunted. Sociodemographic and household characteristics compared by stunting status are presented in Table 1. The majority (91.7\%) of the women who participated in the study were the biological mothers of the infants and their mean age was $27 \cdot 1$ (SD 6.6) years. More than half of the mothers/ caregivers $(55.3 \%)$ were not married and most $(81.3 \%)$ had at least 10 years of schooling (grade 10). Most households had at least one person employed and the median number of beneficiaries of social grants per household was 2 (interquartile range $1-3$ ). The median size of households was 5 (interquartile range 4-7) people.

\section{Breast-feeding and complementary feeding practices}

Table 2 shows the summary of the mother/caregiver's feeding practices for their infants at age 6 months. Nine of the caregivers did not respond to the FFQ, as they were not the full-time caregivers. At age 6 months, $70 \cdot 1 \%$ of the infants were still being breast-fed, with breast milk being either the only milk feed or being given in combination with other milk feeds. Of the 750 infants, 5.9\% were exclusively breast-fed to the recommended age of 6 months.

Among the infants who were already consuming complementary foods ( $n$ 741), the mean age for introducing liquids and semi-solids was 2.5 (SD 1.7) months and 3.8 (SD 1.5) months, respectively. The liquids introduced first ( $n$ 713) were water (53.6\%), formula milk (39.1\%) and a variety of other liquids (rooibos tea, sweetened drink, sugar water, cow's milk; $7 \cdot 3 \%)$. The foods introduced first ( $n$ 701) were commercial infant cereal $(63.8 \%)$, jarred commercial infant foods $(20 \cdot 3 \%)$, maize meal porridge $(8.7 \%)$ and other foods including sorghum porridge, oats porridge and vegetables (7.2\%). Milk feeds given to the infants at the age of 6 months were breast milk only $(52.7 \%)$, breast milk and formula milk (14.9\%), breast milk and cow's milk (2.4\%), formula milk only (27.7\%) and cow's milk only (1.1\%); while $1.2 \%$ received no milk feeds. Foods that were frequently consumed (at least $4 \mathrm{~d}$ during the past week) were infant cereal (68.1\%), sugar $(27 \cdot 9 \%)$ and jarred commercial infant foods (22.7\%). Other complementary foods eaten at least once during the previous week included vegetables $(43.3 \%)$, fruits (26.4\%), eggs (23.9\%), red meat (5.1\%), chicken (28.9\%), liver $(10.5 \%)$ and fish $(2 \cdot 7 \%)$. 
Table 1 Baseline sociodemographic and household characteristics and iron status, and comparison according to stunting, among infants aged 6 months from a peri-urban South African community, September 2013-January 2015

\begin{tabular}{|c|c|c|c|c|c|c|c|}
\hline & \multicolumn{2}{|c|}{ Total $(n 750)$} & \multicolumn{2}{|c|}{ Not stunted (n 536) } & \multicolumn{2}{|c|}{ Stunted ( $n$ 214) } & \multirow[b]{2}{*}{$P \dagger$} \\
\hline & $n$ & $\%$ & $n$ & $\%$ & $n$ & $\%$ & \\
\hline \multicolumn{8}{|l|}{ Caregiver's relationship with infant } \\
\hline Biological mother & 688 & 91.7 & 488 & $91 \cdot 0$ & 200 & 93.5 & 0.749 \\
\hline Grandmother & 32 & $4 \cdot 3$ & 26 & 4.9 & 6 & $2 \cdot 8$ & \\
\hline Aunt & 21 & $2 \cdot 8$ & 16 & 3.0 & 5 & $2 \cdot 3$ & \\
\hline Father & 6 & 0.8 & 4 & 0.7 & 2 & 0.9 & \\
\hline Caregiver not related & 3 & 0.4 & 2 & 0.4 & 1 & 0.5 & \\
\hline \multicolumn{8}{|l|}{ Marital status of mother/caregiver } \\
\hline Not married & 415 & $55 \cdot 3$ & 298 & $55 \cdot 6$ & 117 & 54.5 & 0.328 \\
\hline Living together & 212 & $28 \cdot 3$ & 143 & $26 \cdot 7$ & 69 & $32 \cdot 2$ & \\
\hline Married & 80 & $10 \cdot 7$ & 61 & 11.4 & 19 & 8.9 & \\
\hline Common-law husband/wife & 26 & 3.5 & 19 & 3.5 & 7 & $3 \cdot 3$ & \\
\hline Widower/widow & 10 & 1.3 & 8 & 1.5 & 2 & 0.9 & \\
\hline Separated/divorced & 7 & 0.9 & 7 & 1.3 & 0 & 0.0 & \\
\hline \multicolumn{8}{|l|}{ Level of education } \\
\hline Higher than grade $10($ FET $) \ddagger$ & 601 & $81 \cdot 3$ & 442 & 83.6 & 159 & $75 \cdot 7$ & $0.014^{*}$ \\
\hline Less than grade 10 & 138 & $18 \cdot 7$ & 87 & $16 \cdot 4$ & 51 & $24 \cdot 3$ & \\
\hline Tap water at home & 719 & $95 \cdot 8$ & 513 & $95 \cdot 7$ & 206 & $96 \cdot 3$ & 0.626 \\
\hline Flush toilet at home & 713 & $95 \cdot 1$ & 511 & $95 \cdot 3$ & 202 & 94.4 & 0.703 \\
\hline Electricity at home & 692 & $92 \cdot 3$ & 502 & 93.7 & 190 & 88.8 & $0.024^{*}$ \\
\hline \multicolumn{8}{|l|}{ Iron and Inflammatory status } \\
\hline Anaemic $(n 750) \S$ & 274 & $36 \cdot 5$ & 177 & 33.0 & 97 & $45 \cdot 3$ & $0.002^{*}$ \\
\hline $\mathrm{CRP}>5 \mathrm{mg} / \mathrm{l}(n \mathrm{n} 485)$ & 72 & $14 \cdot 8$ & 50 & $14 \cdot 3$ & 22 & $16 \cdot 3$ & 0.577 \\
\hline$A G P>1 \mathrm{~g} / \mathrm{l}$ & 156 & $32 \cdot 2$ & 104 & 29.7 & 52 & 38.5 & 0.063 \\
\hline ID-PF || & 78 & $16 \cdot 1$ & 50 & $14 \cdot 3$ & 28 & 20.7 & 0.083 \\
\hline ID-sTfRT & 146 & $30 \cdot 1$ & 92 & $26 \cdot 3$ & 54 & $40 \cdot 0$ & $0.002^{*}$ \\
\hline IDA-PF†† & 51 & $10 \cdot 5$ & 31 & 8.9 & 20 & $14 \cdot 8$ & 0.055 \\
\hline IDA-sTfR $\ddagger \ddagger$ & 71 & 14.6 & 41 & 11.7 & 30 & $22 \cdot 2$ & $0.003^{*}$ \\
\hline
\end{tabular}

FET, further education and training; CRP, C-reactive protein; AGP, $a_{1}$-glycoprotein; ID, iron deficiency; PF, plasma ferritin; sTfR, soluble transferrin receptor; IDA, iron-deficiency anaemia.

The cut-offs for anaemia, ID and IDA were based on WHO standards ${ }^{(23)}$

* Significant at $P<0.05$.

$+P$ value from Pearson's $x^{2}$ test.

ҒFET corresponds to more than 10 years of schooling in South Africa.

§Anaemia defined as $\mathrm{Hb}<11 \mathrm{~g} / \mathrm{dl}$.

|ID-PF defined as PF $<12 \mu \mathrm{g} / \mathrm{l}$.

IID-sTfR defined as $\mathrm{sTfR}>8.3 \mathrm{mg} / \mathrm{l}$.

††IDA-PF defined as $\mathrm{Hb}<11 \mathrm{~g} / \mathrm{dl}$ and $\mathrm{PF}<12 \mu \mathrm{g} / \mathrm{l}$.

†¥IDA-STfR defined as $\mathrm{Hb}<11 \mathrm{~g} / \mathrm{dl}$ and $\mathrm{sTfR}>8.3 \mathrm{mg} / \mathrm{l}(n$ 485).

\section{Anthropometric status of the infants and mothers}

Results show that $28.5 \%$ of the infants were stunted, $1.7 \%$ were wasted, $11.1 \%$ were underweight and $10 \cdot 1 \%$ were overweight. Mean anthropometric indices of the total group and comparison according to stunting status are presented in Table 3. Boys had significantly lower mean LAZ ( -1.57 (SD 1.11) v. -1.31 (SD 1.02)) and HCZ (-0.05 (SD 1.05) v. 0.12 (SD 0.95)) than girls. Both sexes had relatively low LAZ and WAZ with reference to the WHO growth standards. Stunted infants had significantly lower $Z$-scores for all anthropometric indicators compared with the non-stunted infants.

Maternal weights and heights were obtained from 539/ 688 (78.3\%) biological mothers. The mean height was 156.8 (SD 6.05$) \mathrm{cm}$. A total of seventy (13\%) mothers had short stature (height $<150 \cdot 1 \mathrm{~cm}$ ). Based on BMI, thirty-one $(5 \cdot 8 \%)$ mothers were underweight, 201 (37.3\%) had normal weight, $165(30 \cdot 6 \%)$ were overweight and 142 (26.3\%) were obese. There was no significant difference in the proportion of stunted infants for mothers of short stature $v$. normal stature (32.9 v. 26.9\%, $P=0.296)$. Although not statistically significant $(P=0 \cdot 118)$, underweight mothers tended to have a greater proportion of stunted children (38.7\%) compared with normal-weight (31.3\%), overweight (26.1\%) and obese (21.8\%) mothers.

\section{Anaemia and iron status of the infants}

Table 1 also shows the prevalence of anaemia, iron deficiency and iron-deficiency anaemia in the study infants. In the present study boys had a higher prevalence of anaemia than girls $(41.3 v \cdot 31.4 \%, P=0.005)$. Stunted infants had a higher prevalence of anaemia than their non-stunted counterparts (45.3 v. 33\%, $P=0.002)$. Stunting was also associated with ID-sTfR $(P=0.002)$ and IDA-sTfR $(P=0.003)$, while there was a trend towards an association with iron deficiency based on ID-PF $(P=0.083)$ and IDA-PF $(P=0.055)$.

\section{Logistic regression for the factors associated with stunting}

The exploratory univariate analysis revealed that the factors significantly associated with stunting were low birth weight $(P<0 \cdot 001)$, male sex $(P=0 \cdot 028)$, education 
Table 2 Feeding practices at 6 months of age, and comparison according to stunting, among infants aged 6 months from a peri-urban South African community, September 2013-January 2015

\begin{tabular}{|c|c|c|c|c|c|c|c|}
\hline \multirow[b]{2}{*}{ Characteristic } & \multicolumn{2}{|c|}{ Total $(n 750)$} & \multicolumn{2}{|c|}{ Not stunted ( $n$ 536) } & \multicolumn{2}{|c|}{ Stunted ( $n$ 214) } & \multirow[b]{2}{*}{$P \dagger$} \\
\hline & $n$ & $\%$ & $n$ & $\%$ & $n$ & $\%$ & \\
\hline \multicolumn{8}{|c|}{ Age, cessation of exclusive breast-feeding } \\
\hline $0-2$ months & 367 & 48.9 & 268 & $50 \cdot 0$ & 99 & $46 \cdot 3$ & \multirow{3}{*}{0.361} \\
\hline 3-4 months & 271 & $36 \cdot 1$ & 194 & $36 \cdot 2$ & 77 & $36 \cdot 0$ & \\
\hline 5-6 months & 112 & 14.9 & 74 & $13 \cdot 8$ & 38 & $17 \cdot 8$ & \\
\hline \multicolumn{8}{|l|}{ Age, milk feeds introduced } \\
\hline $0-2$ months & 159 & 21.4 & 118 & $22 \cdot 3$ & 41 & $19 \cdot 2$ & \multirow{4}{*}{0.186} \\
\hline 3-4 months & 113 & $15 \cdot 2$ & 88 & $16 \cdot 7$ & 25 & 11.7 & \\
\hline 5-6 months & 67 & 9.0 & 46 & 8.7 & 21 & $9 \cdot 8$ & \\
\hline Not started & 403 & $54 \cdot 3$ & 276 & $52 \cdot 3$ & 127 & $59 \cdot 3$ & \\
\hline \multicolumn{8}{|l|}{ Age, other liquids introduced } \\
\hline $0-2$ months & 342 & $45 \cdot 6$ & 248 & $46 \cdot 3$ & 94 & 43.9 & \multirow[t]{4}{*}{0.644} \\
\hline 3-4 months & 253 & $33 \cdot 7$ & 183 & 34.1 & 70 & 32.7 & \\
\hline 5-6 months & 116 & $15 \cdot 5$ & 80 & 14.9 & 36 & $16 \cdot 8$ & \\
\hline Not started & 39 & $5 \cdot 2$ & 25 & 4.7 & 14 & 6.5 & \\
\hline \multicolumn{8}{|c|}{ Age, semi-solid/solid foods introduced } \\
\hline $0-2$ months & 123 & $16 \cdot 6$ & 93 & 17.5 & 30 & $14 \cdot 2$ & \multirow{4}{*}{0.464} \\
\hline 3-4 months & 326 & 43.9 & 227 & $42 \cdot 7$ & 99 & $46 \cdot 9$ & \\
\hline 5-6 months & 249 & 33.6 & 182 & $34 \cdot 3$ & 67 & $31 \cdot 8$ & \\
\hline Not started & 44 & 5.9 & 29 & 5.5 & 15 & $7 \cdot 1$ & \\
\hline \multicolumn{8}{|c|}{ Foods infants consumed (at least once in the previous week) } \\
\hline Formula milk & 352 & 47.5 & 262 & 49.5 & 90 & $42 \cdot 5$ & 0.081 \\
\hline Dairy foods $\ddagger$ & 412 & $55 \cdot 6$ & 299 & $56 \cdot 5$ & 113 & 53.3 & 0.425 \\
\hline Jarred commercial infant foods & 410 & $55 \cdot 3$ & 307 & 58.0 & 103 & 48.6 & $0.019^{*}$ \\
\hline Infant cereals & 596 & $80 \cdot 4$ & 419 & $79 \cdot 2$ & 177 & 83.5 & 0.184 \\
\hline Maize meal porridge§ & 289 & 39.0 & 205 & 38.8 & 84 & 39.6 & 0.826 \\
\hline Fruits and vegetables $\|$ & 462 & $62 \cdot 3$ & 338 & 63.9 & 124 & 58.5 & 0.170 \\
\hline Animal-source foods $\|$ & 223 & $30 \cdot 1$ & 163 & $30 \cdot 8$ & 60 & 28.3 & 0.501 \\
\hline Sweetened cold drinkst† & 173 & 23.3 & 122 & $23 \cdot 1$ & 51 & $24 \cdot 1$ & 0.772 \\
\hline 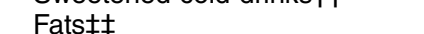 & 398 & 53.7 & 281 & 53.1 & 117 & 55.2 & 0.610 \\
\hline
\end{tabular}

*Significant at $P<0.05$.

† $P$ value from Pearson's $x^{2}$ test.

‡Dairy foods: cow's milk and yoghurt.

§Maize meal porridge: home-prepared maize porridge and instant maize porridge.

Fruits and vegetables: fresh fruits and vegetables and fruit juice.

IAnimal-source foods: red meats, chicken, liver and fish.

††Sweetened cold drinks: fizzy drinks and dilutable drinks.

¥¥Fats: cooking oil and margarine used in preparing infant foods.

level less than grade 10 of the mother/caregiver $(P=0 \cdot 014)$, anaemia $(P=0 \cdot 002)$, ID-sTfR $(P=0.003)$, underweight $(P<0.001)$ and not consuming commercial jarred infant foods at least once during the preceding week ( $P=0.020$; Table 4$)$. These findings guided the development of a multivariable logistic regression analysis model. Maternal height was included in the final model as short mothers had significantly shorter infants (mean $\mathrm{LAZ}=-1.70$ (SD 1.03)) compared with normal-height mothers (mean LAZ $=-1.41$ (SD 1.08); $P=0.033$ ).

The three models for the multivariable logistic regression analysis are summarized in Table 5. Model 1 includes all infants for whom the data for variables in the model were complete and was limited by the data for mother's height ( $n$ 518). Models 2 and 3 include sTfR and AGP, resulting in a smaller sample size ( $n 334,44.5 \%$ ) due to low success with sampling of venous blood in this age group. The results based on model 1 show that boys were 1.73 times more likely to be stunted compared with girls (95\% CI 1.10, 2.70, P=0.014). Stunting showed an inverse relationship with both birth weight $(\mathrm{kg} ; \mathrm{OR}=0 \cdot 12 ; 95 \% \mathrm{CI}$
$0 \cdot 07,0 \cdot 21, P<0.001)$ and maternal height $(\mathrm{cm} ; \mathrm{OR}=0.94$; $95 \%$ CI $0.91,0.98, P=0.001)$. There was a tendency for a negative association between consumption of jarred commercial infant foods and stunting (OR $=0.69 ; 95 \% \mathrm{CI}$ $0 \cdot 44,1 \cdot 07, P=0.099)$. $\mathrm{Hb}(\mathrm{g} / \mathrm{dl})$ and education level of the mother/caregiver showed no association with stunting ( $P>0.05$ ) (Table 5, model 1). Model 3 shows that higher sTfR (mg/l) concentration was associated with higher odds for stunting and there was an inverse association between consumption of jarred commercial infant foods and stunting (Table 5).

\section{Discussion}

The results of the present study show that stunting affected almost a third $(28.5 \%)$ of the study population. This is of public health concern as there is evidence that stunting may result in poor cognitive and physical development, reduced productivity and increased risk of chronic diseases in adulthood ${ }^{(26)}$. Stunting was associated with 
Table 3 Mean anthropometric indices, and comparison according to stunting, among infants aged 6 months from a peri-urban South African community, September 2013-January 2015

\begin{tabular}{|c|c|c|c|c|c|c|c|}
\hline & \multicolumn{2}{|c|}{ Total $(n 750)$} & \multicolumn{2}{|c|}{ Not stunted ( $n$ 536) } & \multicolumn{2}{|c|}{ Stunted (n 214) } & \multirow[b]{2}{*}{$P \dagger$} \\
\hline & Mean & SD & Mean & SD & Mean & SD & \\
\hline LAZ & -1.44 & 1.07 & -0.94 & 0.75 & $-2 \cdot 72$ & 0.60 & $<0.001^{*}$ \\
\hline WLZ & 0.54 & $1 \cdot 15$ & 0.62 & 1.15 & 0.33 & 1.13 & $0.002^{*}$ \\
\hline WAZ & -0.57 & 1.21 & -0.16 & 1.06 & -1.60 & 0.93 & $<0.001^{*}$ \\
\hline BAZ & 0.37 & 1.19 & 0.52 & 1.18 & 0.01 & 1.15 & $<0.001^{*}$ \\
\hline MUACZ & 0.25 & 1.09 & 0.51 & 1.03 & -0.39 & 0.97 & $<0.001^{*}$ \\
\hline $\mathrm{HCZ}$ & 0.03 & 1.00 & 0.28 & 0.92 & -0.57 & 0.97 & $<0.001^{*}$ \\
\hline
\end{tabular}

LAZ, length-for-age Z-score; WLZ, weight-for-length Z-score; WAZ, weight-for-age Z-score; BAZ, BMI-for-age Z-score; MUACZ, mid-upper arm circumferencefor-age $Z$-score; $\mathrm{HCZ}$, head circumference-for-age $Z$-score.

*Significant at $P<0.05$.

$\dagger P$ value from $t$ test.

Table 4 Factors associated with stunting at 6 months of age from univariate logistic regression analysis $(P<0.1)$ among infants from a periurban South African community, September 2013-January 2015

\begin{tabular}{|c|c|c|c|c|c|c|}
\hline & \multirow[b]{2}{*}{$B$} & \multirow[b]{2}{*}{ SE } & \multirow[b]{2}{*}{$P+$} & \multirow[b]{2}{*}{ OR } & \multicolumn{2}{|c|}{$95 \% \mathrm{Cl}$} \\
\hline & & & & & Lower & Upper \\
\hline Male sex (boys) & 0.36 & 0.16 & $0.028^{*}$ & 1.43 & 1.04 & 1.97 \\
\hline Wasted (WLZ <-2) & 0.78 & 0.56 & 0.166 & $2 \cdot 18$ & 0.72 & 6.56 \\
\hline Underweight (WAZ<-2) & 2.53 & 0.28 & $<0.001^{\star}$ & $12 \cdot 55$ & $7 \cdot 22$ & $21 \cdot 82$ \\
\hline Low birth weight $(<2.5 \mathrm{~kg})$ & 1.51 & 0.22 & $<0.001^{*}$ & 4.53 & 2.93 & $7 \cdot 00$ \\
\hline ID-sTfR $(\mathrm{sTfR}>8.3 \mathrm{mg} / \mathrm{l})$ & 0.63 & 0.21 & $0.003^{*}$ & 1.87 & $1 \cdot 23$ & $2 \cdot 84$ \\
\hline Anaemia $(\mathrm{Hb}<11 \mathrm{~g} / \mathrm{dl})$ & 0.52 & 0.16 & $0.002^{*}$ & 1.68 & 1.22 & $2 \cdot 32$ \\
\hline 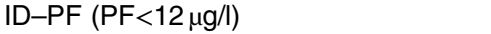 & 0.45 & 0.26 & 0.085 & 1.57 & 0.94 & $2 \cdot 62$ \\
\hline Raised AGP > $1 \mathrm{~g} / \mathrm{l}$ & 0.39 & 0.21 & 0.064 & 1.48 & 0.98 & $2 \cdot 25$ \\
\hline Mother/caregiver education $<10$ years $\ddagger$ & 0.49 & 0.20 & $0.014^{*}$ & 1.63 & $1 \cdot 10$ & $2 \cdot 41$ \\
\hline Maternal height $<150 \cdot 1 \mathrm{~cm}$ & 0.29 & 0.28 & 0.297 & 1.33 & 0.78 & $2 \cdot 28$ \\
\hline \multicolumn{7}{|c|}{ Consumption of foods at least once during the previous week } \\
\hline Fruits and vegetables & -0.23 & 0.17 & 0.170 & 0.80 & 0.58 & 1.10 \\
\hline Infant cereals & 0.28 & 0.21 & 0.185 & 1.33 & 0.87 & 2.02 \\
\hline Jarred commercial infant foods & -0.38 & $0 \cdot 16$ & $0.020^{*}$ & 0.68 & 0.50 & 0.94 \\
\hline Formula milk & -0.29 & 0.16 & 0.082 & 0.75 & 0.55 & 1.04 \\
\hline
\end{tabular}

WLZ, weight-for-length Z-score; WAZ, weight-for-age Z-score; ID, iron deficiency; sTfR, soluble transferrin receptor; PF, plasma ferritin; AGP, $a_{1}$-glycoprotein. *Significant at $P<0.05$.

$\dagger P$ value from univariate binary logistic regression analysis.

†Education<grade 10 for mother/caregiver.

lower birth weight $(P<0 \cdot 001)$, shorter maternal height $(P=0.001)$, male sex $(P=0 \cdot 017)$ and higher sTfR concentrations (mg/l, $P=0.021$; Table 5). These results support the notion that stunting is associated with poor maternal nutritional status and highlights the need for interventions to prevent the intergenerational origins of stunting.

Compared with the WHO cut-off values for public health significance ${ }^{(12)}$, the observed prevalence of stunting (28.5\%), underweight (11.1\%) and wasting (1.7\%) indicate that chronic malnutrition is a problem of public health significance in this community. In a review paper, du Plessis et al. ${ }^{(27)}$ concluded that the high level of stunting in South Africa is a consequence, in part, of poor breastfeeding and complementary feeding practices, and the poor quality of complementary diets. The observed $28.5 \%$ stunting prevalence agrees with findings from the 2012 SANHANES, which found for children 0-3 years old that stunting prevalence for boys and girls was 26.9 and $25.9 \%$, respectively ${ }^{(4)}$. However, stunting at age 6 months and stunting over an age range of $0-3$ years may not be directly comparable, because the prevalence of stunting has been shown to double within the first 2 years of life (28) $^{(28)}$

On the contrary, regional studies involving 6-12-monthold South African infants reported lower prevalence of stunting at $11 \%^{(29)}, 16 \%^{(30)}$ and $13 \%{ }^{(27)}$ in KwaZulu-Natal Province and $12 \%$ in Eastern Cape Province ${ }^{(28)}$. Although these differences may be attributed partly to nonrepresentativeness of the regional data, the observed stunting prevalence supports the view that the epidemiology of stunting varies within a country and between boys and girls. This was also reflected in the 2012 SANHANES data for children under 15 years of age, which showed that overall boys were more stunted than girls, and that the boys from North West Province (23.7\%), for example, had higher prevalence of stunting compared with those from KwaZulu-Natal (13.5\%) and Gauteng (11.9\%) provinces $^{(4)}$.

Logistic regression showed that birth weight $(\mathrm{kg})$ was inversely associated with stunting $(P<0 \cdot 001$, Table 5$)$. This is in line with previous findings and points towards the association between maternal undernutrition, low birth 
weight and stunting in children ${ }^{(2)}$. Maternal short stature, combined with poor nutrition during preconception and pregnancy, may result in small birth size ${ }^{(11,31,32)}$ and subsequent stunting in children $^{(8-10)}$. Maternal short stature may therefore explain to some extent the observed $14.0 \%$ low birth weight and $28.5 \%$ stunting rates in our study. Although there is a need to address postnatal factors associated with stunting, evidence shows that, to prevent stunting, a stronger focus is needed on improving the prenatal environment in order to prevent intra-uterine growth restriction and the occurrence of low birth weight $^{(33,34)}$. This highlights the importance of focusing on women of childbearing age to prevent growth faltering in children.

Multivariable logistic regression analysis showed that boys were 1.73 times $(P=0.017)$ more likely to be stunted than girls (Table 5), which concurs with the findings from sixteen Demographic and Health Surveys from ten sub-Saharan countries ${ }^{(35)}$. The most probable hypothesis explaining why boys are more vulnerable to stunting than girls is that it occurs already during pregnancy, with sex differences in fetal growth ${ }^{(36,37)}$. According to Di Renzo et al., females have a selective advantage over males in utero which is associated with subsequent improved outcomes in the perinatal period; male sex is therefore an independent risk factor for small birth size and other adverse pregnancy outcomes ${ }^{(38)}$. One other plausible explanation for the higher odds of stunting in boys is that they are selectively more vulnerable to environmental infections, resulting in them having increased likelihood for neonatal morbidity compared with female infants ${ }^{(39)}$. Although these hypotheses may partly explain our findings, the underlying mechanisms that predispose boys to higher odds of stunting compared with girls are still poorly understood and speculative.

Infants with higher sTfR $(\mathrm{mg} / \mathrm{l})$ concentrations were 1.12 times more likely $(P=0.021)$ to be stunted than those with lower sTfR $(\mathrm{mg} / \mathrm{l})$ concentrations in logistic regression analysis (model 3, Table 5). The 30.1\% prevalence of iron deficiency based on sTfR observed in the present study may be a more accurate reflection of true iron deficiency, compared with the $16.0 \%$ prevalence based on $\mathrm{PF}^{(25,40)}$. The coexistence of stunting and iron deficiency in the study infants may reflect underlying poor maternal nutrition ${ }^{(41)}$. Interventions aimed at preventing stunting should therefore also focus on preventing anaemia in young and pregnant women, coupled with promotion of breast-feeding and appropriate complementary feeding from age 6 to 23 months to maintain the infant's iron stores $^{(2,42)}$.

A significant number of infants were stunted (28.5\%), anaemic (36.4\%) and/or iron deficient (30.1\% based on ID-sTfR), despite the fact that the majority of infants consumed fortified infant foods. Receiving commercial jarred infant foods at the time of the survey was the only dietary factor that differed between stunted and 
non-stunted infants. However, in the multivariable binary logistic regression analysis, the negative association between consumption of commercial jarred infant foods and stunting was significant only in model 3 (Table 5), which was based on the smaller sample size ( $n$ 334). We acknowledge that consumption of specific complementary foods during the past week does not reflect early feeding practices. It should however be noted that that duration of exclusive breast-feeding $(P=0.361)$ and the age of introducing milk feeds $(P=0 \cdot 186)$, other liquids $(P=0.644)$ and semi/solid foods $(P=0.464)$ did not differ between stunted and non-stunted infants (Table 2 ). At the age of 6 months, most infants have consumed a relatively small total amount of complementary foods and over a relatively short period. It is therefore unlikely that differences in complementary foods consumed could have affected linear growth in our study population.

The early use of commercial infant foods, as observed in the current study, has been previously reported for South African infants ${ }^{(4,5)}$. Early introduction of complementary foods explains the low exclusive breast-feeding rates (5.9\%) observed in our study, which is similar to the 2012 SANHANES findings of $7 \cdot 4 \%$ exclusive breast-feeding ${ }^{(4)}$. Siziba et al. reported $12 \%$ exclusive breast-feeding in four of the nine provinces of South Africa ${ }^{(43)}$. The risk of mixed feeding over exclusive breast-feeding for infants younger than 6 months is an increased risk of infections, which in the long term may lead to stunting via the enteropathy mechanism $^{(44)}$. In addition, stopping breast-feeding and introducing solids before 4 months increases the risk of obesity later in childhood ${ }^{(45)}$. Within the South African context of high HIV/AIDS prevalence and poverty, and high prevalence of obesity, efforts should be made to counter the strong cultural beliefs and other barriers to exclusive breast-feeding $^{(46)}$ as part of a stunting prevention strategy.

The cross-sectional nature of the present study limits ability to make inferences on causation. Other limitations include that the gestational age of infants could not be recorded accurately due to lack of information on health records. Gestational age is important in the interpretation of low birth weight ${ }^{(47,48)}$, therefore the interpretation of low birth weight could have been compromised. Models 2 and 3 of the multivariate analysis are based on only $44.5 \%$ of the total study sample for infants who had all variables included in the models. It is possible that these models in the multivariate analyses could be underpowered. Due to difficulty in obtaining blood samples, sTfR and PF values were available for only 485 (64.7\%) of the 750 infants. Therefore, all iron indicators presented herein except $\mathrm{Hb}$ can be considered exploratory. However, when comparing those with a blood sample ( $n$ 485) and those without a blood sample ( $n$ 266), no significant differences were observed for mother's height $(P=0.678)$ and sex distribution $(P=0 \cdot 619)$, but there was a significant difference between the two groups for low birth weight (52.9 v. $47 \cdot 1 \%, P=0.012)$.
Nevertheless, the present study contributes to the body of knowledge that shows the link between socio-economic factors, maternal factors, feeding practices and stunting in 6-month-old infants from vulnerable populations. Furthermore, the $10 \cdot 1 \%$ prevalence of overweight and $28.5 \%$ prevalence of stunting indicate the presence of the double burden of malnutrition already during infancy and reflect the nutrition transition in South Africa. There is therefore a need for coordinated efforts and effective implementation of existing plans and strategies that focus on the $1000 \mathrm{~d}$ window of opportunity to prevent the long-term consequences of stunting without exacerbating the problem of overweight and obesity.

\section{Conclusions}

The current study showed that the prevalence of stunting (28.5\%) was of public health significance and was significantly associated with lower birth weight, shorter maternal height, male sex and being iron deficient (sTfR). Interventions that focus on improving preconceptual and maternal nutritional status, as well as early feeding practices, may be an important strategy to prevent stunting in infants in vulnerable populations to prevent the long-term consequences of stunting on cognitive, motor and physical development.

\section{Acknowledgements}

Acknowledgements: The authors thank all the parents and caregivers of the infants for participating in the study; the entire Tswaka team for executing the study; Dr Cristiana Berti for her contribution in the planning and early phase of the study; as well as the administrative units of Matlosana Municipality and the Department of Health and local clinics for their collaboration and support. Financial support: The study was funded by Global Alliance for Improved Nutrition (GAIN) and co-funded by Unilever R\&D and DSM. The funding bodies had no influence on the study design, data collection, analysis or interpretation of the data, writing of the manuscript or the decision to submit the manuscript for publication. Conflict of interest: The authors declare no conflict of interest except C.M.S., who received speaking honoraria from Unilever. Authorship: T.M.M. was involved in supervising field data collection and data quality control, data analysis and interpretation of results, and drafted the paper. M.R. contributed to supervising field data collection and quality control for feeding practices data, and review of the paper. C.M.S., M.F. and H.S.K. initiated the study and contributed training, guidance on data collection, quality control and analysis, academic input and review of the paper. All authors read and approved the final manuscript. Ethics of buman subject participation: This study was conducted according to the guidelines laid down in the Declaration of Helsinki and all procedures involving 
human subjects were approved by the Ethics Committees of North-West University (NWU; approval number NWU00001-11-A1) and the South African Medical Research Council (SAMRC; approval number EC-01-03/2012). After institutional ethical approval, the project was reviewed by local authorities. The provincial, district and community's approval to conduct the study was sought through an engagement process with relevant stakeholders. Written informed consent was obtained from the mother or legal guardian of the infant. This study reports baseline data of a randomized controlled trial that was registered at http:// clinicaltrials.gov as NCT01845610.

\section{References}

1. UNICEF, World Health Organization \& World Bank Group (2015) Levels and Trends in Child Malnutrition: Key Findings of the 2015 Edition. New York, Geneva and Washington, DC: UNICEF, WHO and World Bank.

2. Black RE, Victora CG, Walker SP et al. (2013) Maternal and child undernutrition and overweight in low-income and middle-income countries. Lancet 382, 427-451.

3. Said-Mohamed R, Micklesfield LK, Pettifor JM et al. (2015) Has the prevalence of stunting in South African children changed in 40 years? A systematic review. BMC Public Health 15, 534 .

4. Shisana O, Labadarios D, Rehle T et al. (2014) South African National Health and Nutrition Examination Survey (SANHANES-1). Cape Town: HSRC Press.

5. Chopra M, Drimie S \& Witten C (2009) Combating Malnutrition in South Africa. Global Alliance for Improved Nutrition (GAIN), Working Paper Series no. 1. http://www. dbsa.org/EN/About-Us/Publications/Documents/South\% 20Africa\%20Nutrition_\%20input\%20paper_roadmap.pdf (accessed February 2013).

6. Faber M (2005) Complementary foods consumed by 6-12-month-old rural infants in South Africa are inadequate in micronutrients. Public Health Nutr 8, 373-381.

7. Faber M, Laubscher R \& Berti C (2016) Poor dietary diversity and low nutrient density of the complementary diet for 6- to 24-month-old children in urban and rural KwaZulu-Natal, South Africa. Matern Child Nutr 12, 528-545.

8. Özaltin E, Hill K \& Subramanian SV (2010) Association of maternal stature with offspring mortality, underweight, and stunting in low- to middle-income countries. JAMA $\mathbf{3 0 3}$ $1507-1516$.

9. Subramanian SV, Ackerson LK, Davey Smith G et al. (2009) Association of maternal height with child mortality, anthropometric failure, and anemia in india. JAMA 301, 1691-1701.

10. Addo OY, Stein AD, Fall $\mathrm{CH}$ et al. (2013) Maternal height and child growth patterns. J Pediatr 163, 549-554.

11. Catov JM, Bodnar LM, Olsen J et al. (2011) Periconceptional multivitamin use and risk of preterm or small-for-gestationalage births in the Danish National Birth Cohort. Am J Clin Nutr 94, 906-912.

12. Hsieh F (1989) Sample size tables for logistic regression. Stat Med 8, 795-802.

13. World Health Organization (1995) Physical Status: The Use of and Interpretation of Anthropometry. Report of a WHO Expert Committee. WHO Technical Report Series no. 854. Geneva: WHO.

14. World Health Organization (2008) Training Course on Child Growth Assessment. Geneva: WHO.

15. Marfell-Jones M, Stewart A \& de Ridder J (2006) International Standards for Anthropometric Assessment. Potchefstroom: International Society for the Advancement of Kinanthropometry.
16. World Health Organization (2015) Global Database on Body Mass Index: BMI Classification 2006. Geneva: WHO.

17. World Health Organization (2010) Indicators for Assessing Infant and Young Child Feeding Practices: Part 2: Measurement. Geneva: WHO.

18. Erhardt JG, Estes JE, Pfeiffer CM et al. (2004) Combined measurement of ferritin, soluble transferrin receptor, retinol binding protein, and C-reactive protein by an inexpensive, sensitive, and simple sandwich enzyme-linked immunosorbent assay technique. J Nutr 134, 3127-3132.

19. WHO Multicentre Growth Reference Group (2006) WHO Child Growth Standards based on length/height, weight and age. Acta Paediatr Suppl 450, 76-85.

20. De Onis M, World Health Organization (2006) WHO Child Growth Standards: Length/Height-for-Age, Weight-Forage, Weight-for-Length, Weight-for-Height and Body Mass Index-for-Age: Methods and Development. Geneva: WHO.

21. World Health Organization (2011) Optimal Feeding of Low Birth Weight Infants in Low and Middle Income Countries. Geneva: WHO.

22. Onis Md, Onyango AW, Borghi E et al. (2007) Development of a WHO growth reference for school-aged children and adolescents. Bull World Health Organ 85, 660-667.

23. World Health Organization (2011) Haemoglobin Concentrations for the Diagnosis of Anaemia and Assessment of Severity. Geneva: WHO.

24. World Health Organization (2011) Serum Ferritin Concentrations for the Assessment of Iron Status and Iron Deficiency in Populations. Geneva: WHO.

25. Thurnham DI, Northrop-Clewes CA \& Knowles J (2015) The use of adjustment factors to address the impact of inflammation on vitamin A and iron status in humans. J Nutr 145, issue 5, 1137S-1143S.

26. Black RE, Alderman H, Bhutta ZA et al. (2013) Maternal and child nutrition: building momentum for impact. Lancet 382, 372-375.

27. Du Plessis LM, Kruger HS \& Sweet L (2013) Complementary feeding: a critical window of opportunity from six months onwards. S Afr J Clin Nutr 26, issue 3, S129-S140.

28. Smuts CM, Dhansay MA, Faber M et al. (2005) Efficacy of multiple micronutrient supplementation for improving anemia, micronutrient status, and growth in South African infants. J Nutr 135, issue 3, 653S-659S.

29. Faber M \& Spinnler Benadé A (2007) Breastfeeding, complementary feeding and nutritional status of 6-12-month-old infants in rural KwaZulu-Natal. S Afr J Clin Nutr 20, 16-24.

30. Smuts C, Faber M, Schoeman S et al. (2008) Socio-demographic profiles and anthropometric status of 0- to 71-month-old children and their caregivers in rural districts of the Eastern Cape and KwaZulu-Natal provinces of South Africa. S Afr J Clin Nutr 21, 117-124.

31. Gernand AD, Christian P, Paul RR et al. (2012) Maternal weight and body composition during pregnancy are associated with placental and birth weight in rural Bangladesh. I Nutr 142, 2010-2016.

32. Owens S, Gulati R, Fulford AJ et al. (2015) Periconceptional multiple-micronutrient supplementation and placental function in rural Gambian women: a double-blind, randomized, placebo-controlled trial. Am J Clin Nutr 102, 1450-1459.

33. Krishna A, Fink G, Berkman LF et al. (2016) Short- and longrun associations between birth weight and children's height. Econ Hum Biol 21, 156-166.

34. Svefors P, Rahman A, Ekström E-C et al. (2016) Stunted at 10 years. Linear growth trajectories and stunting from birth to pre-adolescence in a rural Bangladeshi cohort. PLOS One 11, e 0149700

35. Wamani H, Åstrøm AN, Peterson S et al. (2007) Boys are more stunted than girls in sub-Saharan Africa: a meta-analysis of 16 demographic and health surveys. BMC Pediatr 7, 17. 
36. Lampl M, Gotsch F, Kusanovic J et al. (2009) Sex differences in fetal growth responses to maternal height and weight. $\mathrm{Am}$ J Hum Biol 22, 431-443.

37. van Abeelen AF, de Rooij SR, Osmond C et al. (2011) The sex-specific effects of famine on the association between placental size and later hypertension. Placenta 32, 694-698.

38. Di Renzo GC, Rosati A, Sarti RD et al. (2007) Does fetal sex affect pregnancy outcome? Gend Med 4, 19-30.

39. Wells JCK (2000) Natural selection and sex differences in morbidity and mortality in early life. $J$ Theor Biol 202, $65-76$.

40. Vázquez-López MA, López-Ruzafa E, Lendinez-Molinos F et al. (2016) Reference values of serum transferrin receptor (sTfR) and sTfR/log ferritin index in healthy children. Pediatr Hematol Oncol 33, 109-120.

41. Menon KC, Ferguson EL, Thomson CD et al. (2016) Effects of anemia at different stages of gestation on infant outcomes. Nutrition 32, 61-65.

42. Bhutta ZA, Das JK, Rizvi A et al. (2013) Evidence-based interventions for improvement of maternal and child nutrition: what can be done and at what cost? Lancet 382, 452-477.
43. Siziba L, Jerling J, Hanekom S et al. (2015) Low rates of exclusive breastfeeding are still evident in four South African provinces. S Afr J Clin Nutr 28, 170-179.

44. Prendergast A, Rukobo S, Chasekwa B et al. (2014) Stunting is characterized by chronic inflammation in Zimbabwean infants (620.4). FASEB J 28, 620-624.

45. Huh SY, Rifas-Shiman SL, Taveras EM et al. (2011) Timing of solid food introduction and risk of obesity in preschoolaged children. Pediatrics 127, e544-e551.

46. Nor B, Ahlberg BM, Doherty $\mathrm{T}$ et al. (2012) Mother's perceptions and experiences of infant feeding within a community-based peer counselling intervention in South Africa. Matern Child Nutr 8, 448-458.

47. Christian P, Lee SE, Donahue Angel M et al. (2013) Risk of childhood undernutrition related to small-for-gestational age and preterm birth in low- and middle-income countries. Int J Epidemiol 42, 1340-1355.

48. Villar J, Ismail LC, Victora CG et al. (2014) International standards for newborn weight, length, and head circumference by gestational age and sex: the Newborn Cross-Sectional Study of the INTERGROWTH-21st Project. Lancet 384, 857-868. 